Check for updates

Cite this: RSC Adv., 2019, 9, 2042

Received 9th October 2018

Accepted 26th December 2018

DOI: $10.1039 / c 8 r a 08369 j$

rsc.li/rsc-advances

\section{An acid-stable positively charged polysulfonamide nanofiltration membrane prepared by interfacial polymerization of polyallylamine and 1,3- benzenedisulfonyl chloride for water treatment $\uparrow$}

\author{
Hao Wang, ${ }^{a}$ Zhong Wei, (D) *abcd Heyun Wang, ${ }^{\text {acd }}$ Haoji Jiang, ${ }^{\text {a }}$ Yinchun Li ${ }^{a}$ \\ and Chunlin $\mathrm{Wu}^{\mathrm{a}}$
}

\begin{abstract}
Here, we selected macromolecular polyallylamine (PAH) as the monomer in an aqueous-phase reaction for the first time, which underwent interfacial polymerization with 1,3-benzenedisulfonyl chloride (BDSC) on the surface of a polyethersulfone (PES) ultrafiltration membrane to prepare a new PSA composite membrane with positive charge, acid stability and high separation performance. By tailoring the polymerization conditions, the desired PSA composite membrane exhibited excellent rejection of different salts $\left[\mathrm{MgCl}_{2}(92.44 \%)>\mathrm{MgSO}_{4}(89.2 \%)>\mathrm{NaCl}(56.8 \%)>\mathrm{Na}_{2} \mathrm{SO}_{4}(55.2 \%)\right]$ and a high permeation flux of up to $34.10 \mathrm{~L} \mathrm{~m}^{-2} \mathrm{~h}^{-1}$ at $0.5 \mathrm{MPa}$. The properties of the membrane were evaluated using various characterization techniques. The results indicated that the new PSA membrane is more positively charged and more compact than reported PSA composite membranes. In addition, it exhibited high acid stability. After exposure to a $20 \%(\mathrm{w} / \mathrm{v}) \mathrm{H}_{2} \mathrm{SO}_{4}$ solution for 30 days, the $\mathrm{MgCl}_{2}$ rejection level reached $88.3 \%$. Finally, we used the new PSA composite membrane to test some heavy metal ions and found that the rejection level was always greater than $90 \%$. Therefore, the new PSA composite membrane exhibited potential for water desalination and the removal of heavy metal ions from an acidic environment.
\end{abstract}

\section{Introduction}

Water treatment and purification have become global problems owing to the rapid development of industries around the world, the excessive rise in population and environmental pollution. Membrane technologies, such as microfiltration (MF), ultrafiltration (UF), nanofiltration (NF), reverse osmosis (RO), and membrane distillation (MD), have been widely employed for water treatment in recent decades. ${ }^{\mathbf{1 , 2}}$ Membrane technologies have some advantages in comparison with other methods, such as energy efficiency, ease of operation, strong separation effects and environment-friendliness. ${ }^{2-4}$ Among these membrane technologies, NF is a pressure-driven filtration technique that uses membranes with charge characteristics (positive or

${ }^{a}$ School of Chemistry and Chemical Engineering, Shihezi University, Shihezi 832003, China. E-mail: steven_weiz@sina.com; whyun@shzu.edu.cn; Fax: +86-09932057272; Tel: +8617799434147

${ }^{b}$ Key Laboratory for Green Processing of Chemical Engineering of Xinjiang Bingtuan, Shihezi University, Shihezi 832003, China

'Key Laboratory of Materials-Oriented Chemical Engineering of Xinjiang Uygur Autonomous Region, China

${ }^{d}$ Engineering Research Center of Materials-Oriented Chemical Engineering of Xinjiang Uygur Autonomous Region, China

$\uparrow$ Electronic supplementary information (ESI) available. See DOI: 10.1039/c8ra08369j negative), as well as nanoscale pore sizes of around $0.5-2 \mathrm{~nm}$, which are intermediate between those used in RO and UF. ${ }^{5-7}$ These two characteristics of NF membranes enable their unique separation mechanism, including both size exclusion and the Donnan effect. ${ }^{\mathbf{1} 8}$ It is worth mentioning that only the size exclusion effect is considered for the separation of neutral solutes (such as carbohydrates, alcohols, and phenols) through NF membranes, and similarly only the Donnan effect is considered for the separation of electrolyte solutes (such as inorganic salts) through NF membranes by assuming that the membrane's pore radius is much larger than the size of the electrolyte. ${ }^{9-11}$ Therefore, NF membranes are widely used in desalination, water softening, environmental protection, heavy metal removal, and pharmacy. ${ }^{5-7}$

To date, many kinds of method have been used for the preparation of NF membranes, such as coating, ${ }^{12,13}$ layer-bylayer assembly, ${ }^{14}$ surface grafting, ${ }^{15}$ and interfacial polymerization (IP).${ }^{6,7}$ Among these methods, IP has been the main method used for preparing NF membranes because it has several advantages. These include the fact that the IP process is fast and easy to perform. In addition, a thin-film composite membrane with high water flux and salt rejection can be obtained by IP. ${ }^{16,17}$ At present, polyamide (PA) is the commonest commercial NF membrane material formed via IP. ${ }^{\mathbf{1 , 1 7}}$ However, PA composite membranes still have two disadvantages in practical 
applications: firstly, most of the surfaces of PA composite membranes are currently negatively charged, which results in poor performance of PA membranes in the separation of divalent metal ions from wastewater. ${ }^{\mathbf{1 , 1 8}}$ According to the Donnan effect, it is beneficial to separate divalent metal ions with positively charged NF membranes. In general, the positively charged nature of NF membrane materials is closely related to the monomer used in the aqueous-phase reaction. Wang ${ }^{19}$ prepared two kinds of NF membranes using $\beta$-cyclodextrin functionalized with multiple ethylenediamine groups $(\beta-C D-$ EDA) and $\beta$-cyclodextrin ( $\beta$-CD) used separately as an aqueous monomer to react with trimesoyl chloride (TMC). The results showed that the $\beta$-CD-EDA membrane had a higher zetapotential than that of the $\beta$-CD membrane, which indicated that there were more positive charges on the membrane surface. Chiang $^{20}$ chose ethylenediamine (EDA), diethylenetriamine (DETA), and hyperbranched polyethyleneimine (PEI) to react with TMC to prepare three kinds of PA composite membranes. This experiment showed that PA membranes prepared using small-molecule amines (EDA, DETA) were negatively charged on their surfaces; in contrast, using a macromolecular amine (PEI) to prepare a PA membrane resulted in positive charges on surfaces. This result could be explained by the fact that PEI is a macromolecule, and hence its speed of diffusion into the organic phase was slower than that of small-molecule amines (EDA, DETA). Furthermore, PEI has lower reactivity with TMC than EDA and DETA, and thus the surfaces of the newly produced PA membrane had many unreacted amine groups that provided positively charged sites. In addition to PEI,, $\mathbf{1 2 0 , 2 1}$ other macromolecular amines are available as monomers for aqueous-phase reactions, including polyamidoamine (PAMAM), ${ }^{22,23}$ polyvinylamine (PVAm), ${ }^{24,25}$ amino-functionalized polyethylene glycol (PEG) ${ }^{26}$ and polyhexamethylene guanidine hydrochloride (PHGH). ${ }^{27}$ These can be used to prepare positively charged NF membranes, which all exhibit rejection of $\mathrm{Mg}^{2+}$ of greater than $90 \%$. A second disadvantage of PA composite membranes is that the amide bonds are easily hydrolyzed in acidic environments, which results in a rapid decline in the membrane separation effect. ${ }^{28-31}$ This result is attributed to the fact that the electronegativity of the oxygen atom in the amide bond is higher than that of the carbon atom, and hence the carbonyl group is much more susceptible to nucleophilic attack in acidic conditions. ${ }^{28,29}$ Thus, this disadvantage limits the utility of PA membranes in many applications that involve strongly acidic conditions, such as the electroplating industry, ${ }^{32,33}$ the recovery of metals from acid wastes, ${ }^{34}$ the recovery of acidic bleaching water in the paper industry ${ }^{35}$ and the removal of nitrogenous compounds from acidic wastewater. $^{36}$ Therefore, it would be desirable to prepare acidstable NF membranes. At present, polymers with sulfonated aromatic groups are the commonest commercially available acid-stable membrane materials. ${ }^{37,38}$ However, this kind of membrane has relatively low permeation fluxes or low salt rejections. Recently, a kind of polymer with an s-triazine ring structure has been used as an acid-stable membrane material. Some membranes with this kind of structure have been formed via IP between cyanuric chloride (CC) and amines. ${ }^{28,29}$ However, these NF membranes exhibited a relatively low permeation flux (1.5 $\mathrm{L} \mathrm{m}^{-2} \mathrm{~h}^{-1}$ bar $^{-1}$ ), which is unfavorable in scaled-up practical applications. Polysulfonamide (PSA) is another acid-stable membrane material and is used for water treatment in extreme conditions. It has been reported to exhibit higher acid stability than PA composite membranes, ${ }^{30}$ which was attributed to the stable chemical structure of the sulfonamide bond in acidic conditions. Liu ${ }^{31}$ developed membranes based on a PSA structure via an IP reaction between naphthalene-1,3,6-trisulfonyl chloride (NTSC) and piperazine (PIP). The separation performance of this kind of PSA membrane changed only slightly after exposure to a $20 \%(\mathrm{w} / \mathrm{v}) \mathrm{H}_{2} \mathrm{SO}_{4}$ solution for 60 days; hence, this kind of membrane exhibited excellent acid stability. However, the separation performance of PSA composite membranes is poor, with a rejection of $\mathrm{Mg}^{2+}$ of only around $40 \% .^{31,39}$ The poor separation performance of PSA membranes is due to the low reactivity of sulfonyl chlorides, which results in PSA membranes with low cross-linking levels. The coating of PSA membranes is largely formed from linear low-molecular-weight polymers with few pendant groups. ${ }^{40}$ In addition, a sulfonyl chloride is easily hydrolyzed to a sulfonic acid, which provides negatively charged sites, with the result that the surfaces of PSA membranes have negative charges. $^{\mathbf{3 0 , 3 1 , 3 9 , 4 1}}$ These disadvantages of PSA membranes have limited their use in some large-scale practical applications, especially in dealing with divalent metal ions or heavy metal ions. Hence, the improvement of the separation performance of PSA membranes is an urgent problem.

In this study, we intended to design a new type of PSA composite membrane to solve the problem of the poor separation performance of reported PSA composite membranes. The macromolecule PAH was used for the first time as the monomer in an aqueous-phase reaction and reacted with 1,3-benzenedisulfonyl chloride (BDSC) on the surface of a PES substrate via IP to prepare a new PSA composite membrane with positive charges, acid stability, and high performance. The polymerization conditions, including the $\mathrm{pH}$ of the aqueous-phase solution, soaking time in the aqueous-phase solution, reaction time, and concentration of the reaction monomer, were systematically investigated. The properties of the PSA composite membrane were evaluated using ATR-FTIR, XPS, zeta potential measurements, SEM, AFM and the molecular weight cut-off (MWCO). Finally, the separation performance and acid stability of the membrane were systematically tested.

\section{Experimental}

\subsection{Materials}

Polyethersulfone ultrafiltration (PES UF) membranes with an MWCO of 30000 Da were supplied by Zhongcorui Film Technology (Beijing) Co., Ltd. Polyallylamine hydrochloride (PAH, powder, $\mathrm{MW}=17500 \mathrm{Da}$, purity 98\%) and 1,3-benzenedisulfonyl chloride (BDSC, purity 98\%) were supplied by SigmaAldrich. Isopar G (isoparaffin-type hydrocarbon oil) was supplied by DiKaiMu Chemical Ltd., China. 4-Dimethylaminopyridine (DMAP) and sodium dodecyl sulfate (SDS) were supplied by Shantou Xilong Chemical Factory, China. Polyethylene glycol (PEG) (MW = 200, 400, 800, 2000, 4000, 6000, 
and $10000 \mathrm{Da}$ ) was supplied by TCI. Inorganic salt solutions ( $\mathrm{NaCl}, \mathrm{Na}_{2} \mathrm{SO}_{4}, \mathrm{MgSO}_{4}, \mathrm{MgCl}_{2}, \mathrm{CuCl}_{2}, \mathrm{ZnCl}_{2}, \mathrm{CdCl}_{2}$, and $\left.\mathrm{Pb}\left(\mathrm{NO}_{3}\right)_{2}\right)$ were supplied by Adamas.

\subsection{Fabrication of PSA composite membrane}

The detailed fabrication process was as follows: firstly, PES UF membranes were used as the substrates and were immersed in deionized (DI) water for $24 \mathrm{~h}$ and then dried. Secondly, aqueousphase solutions containing certain amounts of PAH, $0.2 \%(\mathrm{w} / \mathrm{v})$ DMAP as a catalyst and $0.025 \%(\mathrm{w} / \mathrm{v})$ SDS were fabricated and their $\mathrm{pH}$ adjusted with $\mathrm{NaOH}$. Then, the PES substrates were immersed in the aqueous-phase solutions for a certain period. After the excess solutions were removed, the PAH-coated substrates were dried at room temperature until no liquid remained. Thirdly, the BDSC solution was applied to the surface of the PAH-coated substrates for a certain period to initiate interfacial polymerization. The excess solutions were drained, and the initial membranes were washed four times with Isopar $\mathrm{G}$ solvent to remove residual BDSC from the membrane surfaces. Next, the initial membranes were heated at $95{ }^{\circ} \mathrm{C}$ for $10 \mathrm{~min}$. Finally, the newly obtained PSA composite membranes were washed four times with deionized water and stored in deionized water until tested.

\subsection{Characterization of PSA composite membrane}

Scanning electron microscopy (SEM, U8020, Japan) was used to examine the surface and cross-section morphologies of the membrane. The surface roughness of the membrane was examined by atomic force microscopy (AFM, MultiMode 8, Germany). The chemical bonds on the membrane surface were examined by attenuated total reflectance Fourier transform infrared spectrometry (ATR-FTIR, Bio-Rad FTS-6000, USA). Next, the chemical composition of the membrane surface was further examined by X-ray photoelectron spectroscopy (XPS, PerkinElmer PHI 5000C ESCA System, USA) using an Mg K $\alpha 1,2$ radiation source. The spectra were recorded over the range of 0 to $1200 \mathrm{eV}$. The water contact angles of the membranes were determined using a contact angle goniometer (Kruss Easy Drop, Germany) at room temperature. Finally, the surface zeta potential of the membrane was examined with an electrokinetic analyzer (Anton Paar GmbH, Austria). The electrokinetic analysis was performed with $1 \mathrm{mmol} \mathrm{L}^{-1} \mathrm{KCl}$ as the electrolyte solution. The $\mathrm{pH}$ of the electrolyte solution was adjusted using $\mathrm{NaOH}$ and $\mathrm{HCl}$ solutions.

\subsection{Evaluation of performance of PSA composite membrane}

The separation performance of the NF membrane was measured using a laboratory-made cross-flow flat membrane system. The effective area of the membrane was $12.56 \mathrm{~cm}^{2}$. Each membrane was pressurized at $0.6 \mathrm{MPa}$ with pure water for $2 \mathrm{~h}$ before the performance of the membrane was evaluated. Inorganic salt solutions ( $\mathrm{NaCl}, \mathrm{Na}_{2} \mathrm{SO}_{4}, \mathrm{MgSO}_{4}, \mathrm{MgCl}_{2}, \mathrm{CuCl}_{2}, \mathrm{ZnCl}_{2}$, $\mathrm{CdCl}_{2}$, and $\mathrm{Pb}\left(\mathrm{NO}_{3}\right)_{2}$ ) and PEG solutions were used as feed solutions for a permeation test at $0.5 \mathrm{MPa}$ and room temperature. In addition, to ensure reproducibility, the performance results were average values recorded for more than three samples of each type of membrane. The permeation flux $(F, \mathrm{~L}$ $\left.\mathrm{m}^{-2} \mathrm{~h}^{-1}\right)$ and rejection $(R, \%)$ of the membrane were calculated as follows:

$$
\begin{gathered}
F=\frac{V}{A t} \\
\text { Permeate }=\frac{F}{\Delta P}=\frac{V}{A t \Delta P} \\
\Delta P=P-\pi=P-(i \Delta M R T)
\end{gathered}
$$

where $V, A$, and $t$ represent the permeation volume (L), the membrane area $\left(\mathrm{m}^{2}\right)$, and the filtration time (h), respectively. $\Delta P, P$, and $\pi$ represent the effective transmembrane pressure, practical pressure (MPa), and osmotic pressure, respectively. $\Delta M, i, R$ and $T$ represent the difference in the molar concentration of the solute between the feed and permeate $\left(\mathrm{mol} \mathrm{L}^{-1}\right)$, the van't Hoff factor for the relevant solute, the universal gas constant $\left(0.08314 \mathrm{~L}\right.$ bar $\left.\mathrm{mol}^{-1} \mathrm{~K}^{-1}\right)$, and the absolute temperature $(\mathrm{K})$, respectively.

$$
R=\left(1-\frac{C_{\mathrm{p}}}{C_{\mathrm{f}}}\right) \times 100 \%
$$

where $C_{\mathrm{p}}$ and $C_{\mathrm{f}}$ are the solute concentrations $\left(\mathrm{g} \mathrm{L}^{-1}\right)$ of the permeate and feed solutions, respectively.

The MWCO of the membrane was determined using solutions of PEG with different molecular weights that were uncharged. The membrane pore sizes were calculated by the Donnan steric pore model (DSPM). According to this model, the rejection of uncharged solutes is given by: ${ }^{28,29}$

$$
\begin{gathered}
R_{\mathrm{p}}=\left(1-\Phi K_{\mathrm{i}, \mathrm{c}}\right) \times 100 \% \\
\lambda=\frac{r_{\mathrm{i}}}{r_{\mathrm{p}}} \\
\Phi=\left(1-\lambda^{2}\right) \\
K_{\mathrm{i}, \mathrm{c}}=(2-\Phi)\left(1.0+0.054 \lambda-0.988 \lambda^{2}+0.441 \lambda^{3}\right)
\end{gathered}
$$

The empirical relation based on the molecular weight (MW, Da) is as follows: ${ }^{29}$

$$
\log r_{\mathrm{i}}=-1.3363+0.395 \log \mathrm{MW}
$$

where $R_{\mathrm{p}}, \Phi, K_{\mathrm{i}, \mathrm{c}}, \lambda, r_{\mathrm{p}}, r_{\mathrm{i}}$ and MW are the rejection of the solute, the steric partitioning coefficient, the steric hindrance factor, the ratio between the solute radius and pore radius, the pore radius $(\mathrm{nm})$, the Stokes radius of the solute $(\mathrm{nm})$, and the molecular weight (Da), respectively.

PEG concentration data were obtained by spectrometric titration. ${ }^{42}$ Salt concentration data were obtained by measuring the conductivity using a DDSJ-307A conductivity meter (Shanghai Leichi Instruments, China).

The acid stability of the membranes was determined using a method developed by other researchers. ${ }^{31}$ The detailed process was as follows: firstly, the membranes were exposed to a $20.0 \%(\mathrm{w} / \mathrm{v}) \mathrm{H}_{2} \mathrm{SO}_{4}$ solution at room temperature for fixed 
periods. Secondly, the membranes were taken out from the acid solution and washed with DI water. Finally, the membrane samples were immersed in DI water until tested.

\section{Results and discussion}

\subsection{Optimization of polymerization conditions}

We know that the performance of NF membranes is determined by the chemistry and conditions of polymerization of the active separation layer during processing by IP, in which the polymerization conditions play a major role in determining the compactness, thickness, and degree of cross-linking of the active separation layer and hence the separation effect of the membrane. ${ }^{6,24,43}$ Therefore, tailoring the polymerization conditions, such as the $\mathrm{pH}$ of the aqueous-phase solution, soaking time in the aqueous-phase solution, reaction time, and concentration of the reaction monomer, was necessary and provided the optimum polymerization conditions for the fabrication of the new PSA composite membranes. The chemical structure of the expected active separation layer of the PSA composite membranes is shown in Scheme 1.

3.1.1 pH of РAH aqueous-phase solution. Fig. 1 shows the effect of the $\mathrm{pH}$ of the $\mathrm{PAH}$ aqueous-phase solution on the separation performance of the PSA composite membranes. The permeation flux decreased dramatically from 61.8 to $33.8 \mathrm{~L} \mathrm{~m}^{-2}$ $\mathrm{h}^{-1}$ as the $\mathrm{pH}$ was increased from 8.5 to 9.33 , and the $\mathrm{NaCl}$ rejection increased from $17.8 \%$ to $55.9 \%$. However, the separation performance of the membrane exhibited the opposite trend as the $\mathrm{pH}$ was increased to 9.7 .

This result could be explained by the fact that more amino groups $\left(-\mathrm{NH}_{2}\right)$ in the $\mathrm{PAH}$ macromolecule were initially protonated at a low $\mathrm{pH}$ than at high $\mathrm{pH}$ values. This protonation was unfavorable to the IP reaction. Increasing the $\mathrm{pH}$ reduced the degree of protonation and allowed the $-\mathrm{NH}_{2}$ groups to participate in the reaction to form PSA polymers with abundant cross-links. This resulted in the formation of a compact PSA

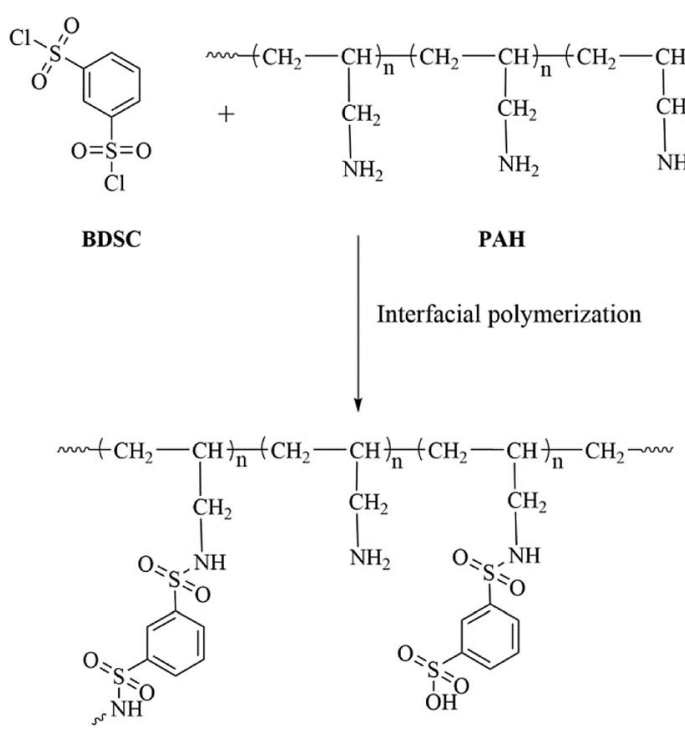

Scheme 1 Structure of the PSA active separation layer formed by interfacial polymerization between PAH and BDSC.

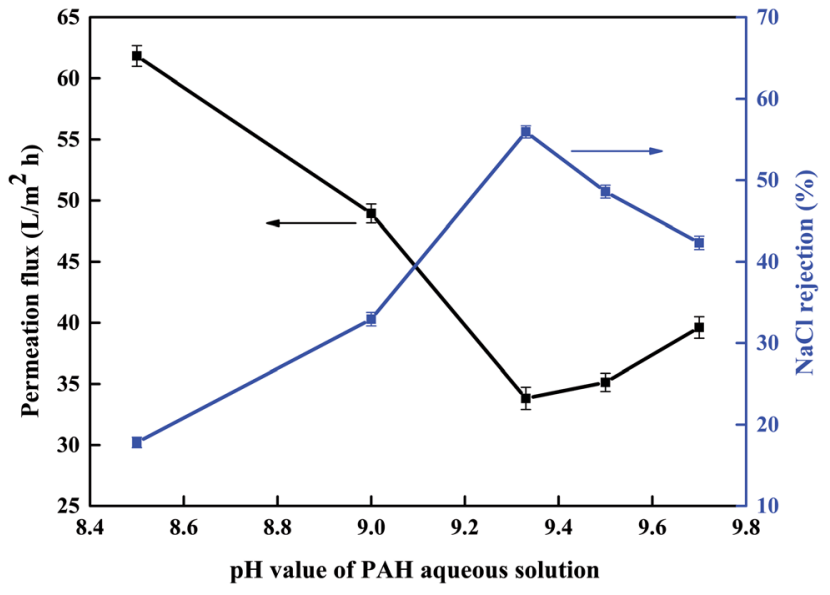

Fig. 1 Effect of the $\mathrm{pH}$ of the $\mathrm{PAH}$ aqueous solution on the separation performance of the PSA composite membrane evaluated with a $1 \mathrm{~g} \mathrm{~L}^{-1}$ $\mathrm{NaCl}$ solution at $0.5 \mathrm{MPa}$ and room temperature (polymerization conditions: $\mathrm{PAH}$ concentration $0.7 \%(\mathrm{w} / \mathrm{v})$, soaking time in $\mathrm{PAH}$ aqueous solution $60 \mathrm{~min}, \mathrm{BDSC}$ concentration $0.1 \%(\mathrm{w} / \mathrm{v})$, reaction time $20 \mathrm{~min}$ ).

active separation layer on the PES substrate, which thus produced membranes with a high rejection and a low permeation flux. However, as the $\mathrm{pH}$ was increased to 9.7, the sulfonyl chloride groups were easily hydrolyzed. The hydrolysis of BDSC led to the formation of a less highly cross-linked and looser PSA active separation layer and thereby produced a membrane with a low rejection and a high permeation flux. According to our tests on the resulting membranes, the optimum $\mathrm{pH}$ of the $\mathrm{PAH}$ aqueous-phase solution is around 9.33.

3.1.2 Soaking time in PAH aqueous solution. Next, we investigated the soaking time of the PES membrane support in the PAH aqueous solution and its effect on the separation performance of the new PSA composite membranes. The resulting data are shown in Fig. 2. As the soaking time in the $\mathrm{PAH}$ aqueous solution was increased from 5 to 25 minutes, the permeation flux decreased from about 53.1 to $34.2 \mathrm{~L} \mathrm{~m}^{-2} \mathrm{~h}^{-1}$,

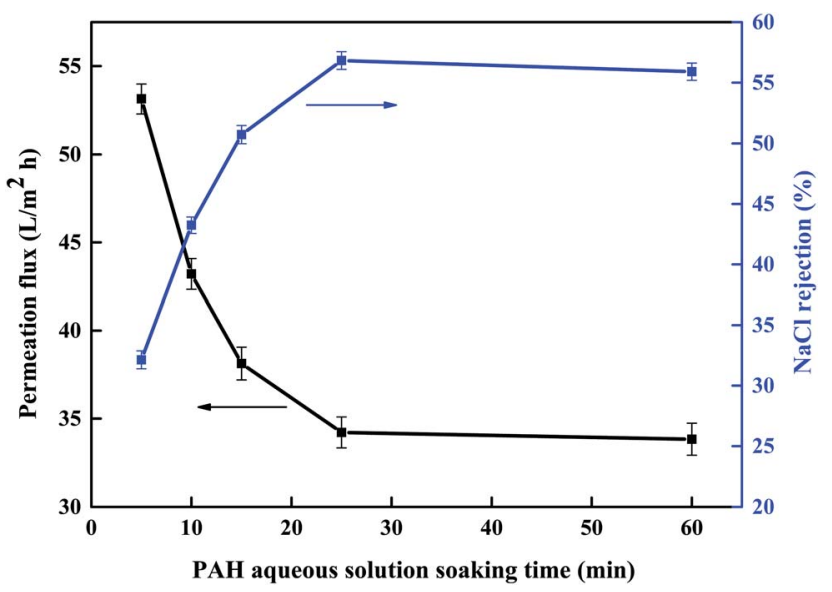

Fig. 2 Effect of the soaking time in the PAH aqueous solution on the separation performance of the PSA composite membrane evaluated with a $1 \mathrm{~g} \mathrm{~L}^{-1} \mathrm{NaCl}$ solution at $0.5 \mathrm{MPa}$ and room temperature (polymerization conditions: PAH concentration $0.7 \%(\mathrm{w} / \mathrm{v}), \mathrm{pH} 9.33, \mathrm{BDSC}$ concentration $0.1 \%(\mathrm{w} / \mathrm{v})$, reaction time $20 \mathrm{~min})$. 


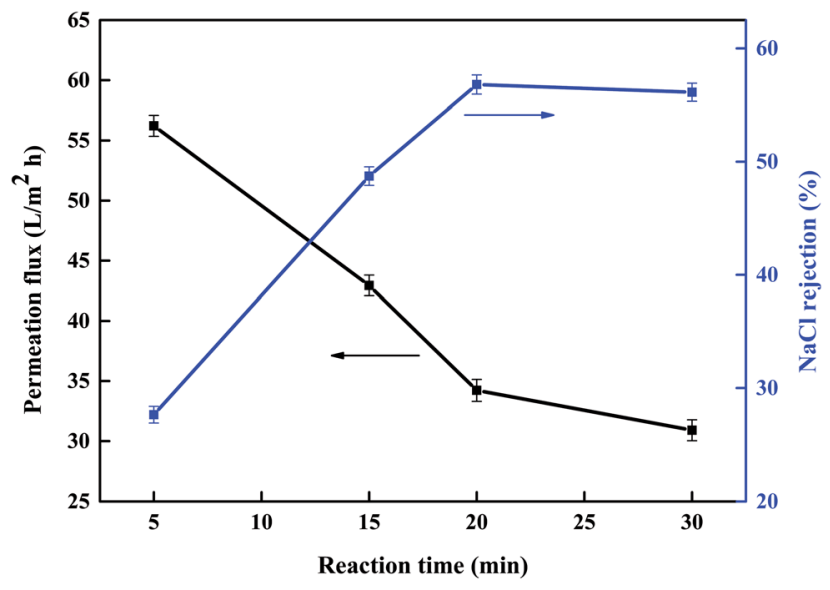

Fig. 3 Effect of reaction time on the separation performance of the PSA composite membrane evaluated with a $1 \mathrm{~g} \mathrm{~L}^{-1} \mathrm{NaCl}$ aqueous solution at $0.5 \mathrm{MPa}$ and room temperature (polymerization conditions: $\mathrm{PAH}$ concentration $0.7 \%(\mathrm{w} / \mathrm{v}), \mathrm{pH}$ 9.33, BDSC concentration $0.1 \%$ $(\mathrm{w} / \mathrm{v})$, soaking time in $\mathrm{PAH}$ aqueous solution $25 \mathrm{~min})$.

and the $\mathrm{NaCl}$ rejection increased from $32.1 \%$ to $56.8 \%$. However, the $\mathrm{NaCl}$ rejection and permeation flux changed only slightly as the time was increased to 60 minutes.

This result could be explained by the fact that the soaking of the PES substrate in the PAH aqueous solution comprised an adsorption process owing to the porous nature of the PES substrate. In a short soaking process, the PES substrate adsorbed less macromolecular PAH, which reacted with BDSC to form a loose PSA active separation layer on the substrate and thereby produced a membrane with a high permeation flux and a low $\mathrm{NaCl}$ rejection. As the soaking time increased, more macromolecular PAH was adsorbed onto the PES substrate to form a PAH top layer. This top layer reacted with BDSC to form a compact PSA active separation layer on the PES substrate, which resulted in a membrane with a high $\mathrm{NaCl}$ rejection and a low permeation flux. However, with a further increase in the soaking time, the adsorption of PAH by the PES substrate may have reached saturation, which had only a slight effect on the performance of the PSA composite membranes. According to our tests on the resulting membranes, the optimum soaking time in the PAH aqueous solution is 25 minutes.
3.1.3 Reaction time. On the basis of the above results, we also investigated the reaction time and its effect on the separation performance of the new PSA composite membranes. The experimental results are shown in Fig. 3. The permeation flux decreased rapidly from 56.2 to $34.2 \mathrm{~L} \mathrm{~m}^{-2} \mathrm{~h}^{-1}$ when the reaction time was increased from 5 to 20 minutes, and the $\mathrm{NaCl}$ rejection increased rapidly from $27.6 \%$ to $56.8 \%$. As the reaction time was increased to 30 minutes, the changes in the separation performance were only slight.

According to the literature,$^{25,44}$ the growth of the IP active separation layer is self-limited because the formation of a compact and thick active separation layer hinders further diffusion of the reaction monomer from one phase to another immiscible phase. Because the reactivity of sulfonyl chloride groups is low, the extent of the reaction between PAH and BDSC was low at short reaction times and the PSA active separation layer on the PES substrate was loose, which thus produced membranes with a high permeation flux and a low $\mathrm{NaCl}$ rejection. As the reaction time was increased, the extent of the reaction increased, which led to the formation of a compact and thick PSA active separation layer on the PES substrate and thus produced membranes with a low permeation flux and a high $\mathrm{NaCl}$ rejection. However, when the reaction time was further increased, this had little effect on the performance of the membrane because the compactness and thickness of the PSA active separation layer on the PES substrate were almost constant. According to our tests on the resulting membranes, the optimum reaction time is 20 minutes.

3.1.4 Reaction monomer concentration. The concentration of the reaction monomer plays important roles in determining the extent of IP and therefore in determining the compactness and thickness of the active separation layer and hence the separation performance of the membrane. ${ }^{25}$ Hence, we studied the concentrations of PAH and BDSC and their effects on the separation performance of the PSA composite membrane. Table 1 shows the experimental results. It can be clearly seen that there was a sharp decrease in the permeation flux from 51.8 to $42.2 \mathrm{~L} \mathrm{~m}^{-2} \mathrm{~h}^{-1}$ as the PAH concentration was increased from $0.1 \%$ to $0.7 \%(\mathrm{w} / \mathrm{v})$, and the $\mathrm{MgCl}_{2}$ rejection increased from $65.8 \%$ to $72.5 \%$ at a fixed BDSC concentration of $0.02 \%(\mathrm{w} / \mathrm{v})$. As the concentration of the PAH aqueous solution was increased to $1 \%(\mathrm{w} / \mathrm{v})$, the permeation flux increased to $56.6 \mathrm{~L} \mathrm{~m}^{-2} \mathrm{~h}^{-1}$ and

Table 1 Effects of PAH and BDSC concentrations on the separation performance and water contact angle of the PSA composite membrane evaluated with a $1 \mathrm{~g} \mathrm{~L}^{-1} \mathrm{MgCl}_{2}$ solution at $0.5 \mathrm{MPa}$ and room temperature (polymerization conditions: $\mathrm{pH}$ 9.33, soaking time in PAH aqueous solution $25 \mathrm{~min}$, reaction time $20 \mathrm{~min}$ )

\begin{tabular}{|c|c|c|c|c|c|}
\hline Composite membrane & $\mathrm{PAH}(\mathrm{w} / \mathrm{v}, \%)$ & BDSC (w/v, \%) & $\mathrm{MgCl}_{2}$ rejection (\%) & $\begin{array}{l}\text { Permeation flux } \\
\left(\mathrm{L} \mathrm{m}^{-2} \mathrm{~h}^{-1}\right)\end{array}$ & Contact angle $\left(^{\circ}\right)$ \\
\hline PES & 0 & 0 & $3.2 \pm 0.88$ & $160.10 \pm 1.2$ & $70.8 \pm 2.08$ \\
\hline NF1 & 0.1 & 0.02 & $65.75 \pm 0.65$ & $51.75 \pm 0.88$ & $81.2 \pm 2.12$ \\
\hline NF2 & 0.4 & 0.02 & $70.01 \pm 0.67$ & $45.37 \pm 0.82$ & $82.6 \pm 1.84$ \\
\hline NF3 & 0.7 & 0.02 & $72.49 \pm 0.67$ & $42.20 \pm 0.81$ & $83.1 \pm 1.92$ \\
\hline NF4 & 1 & 0.02 & $53.08 \pm 0.47$ & $56.61 \pm 0.75$ & $80.7 \pm 1.83$ \\
\hline NF5 & 0.7 & 0.06 & $80.46 \pm 0.6$ & $39.44 \pm 0.84$ & $85.3 \pm 2.10$ \\
\hline NF6 & 0.7 & 0.1 & $92.44 \pm 0.73$ & $34.10 \pm 0.75$ & $88.7 \pm 1.79$ \\
\hline NF7 & 0.7 & 0.14 & $91.20 \pm 0.6$ & $31.30 \pm 0.86$ & $93.8 \pm 1.67$ \\
\hline
\end{tabular}



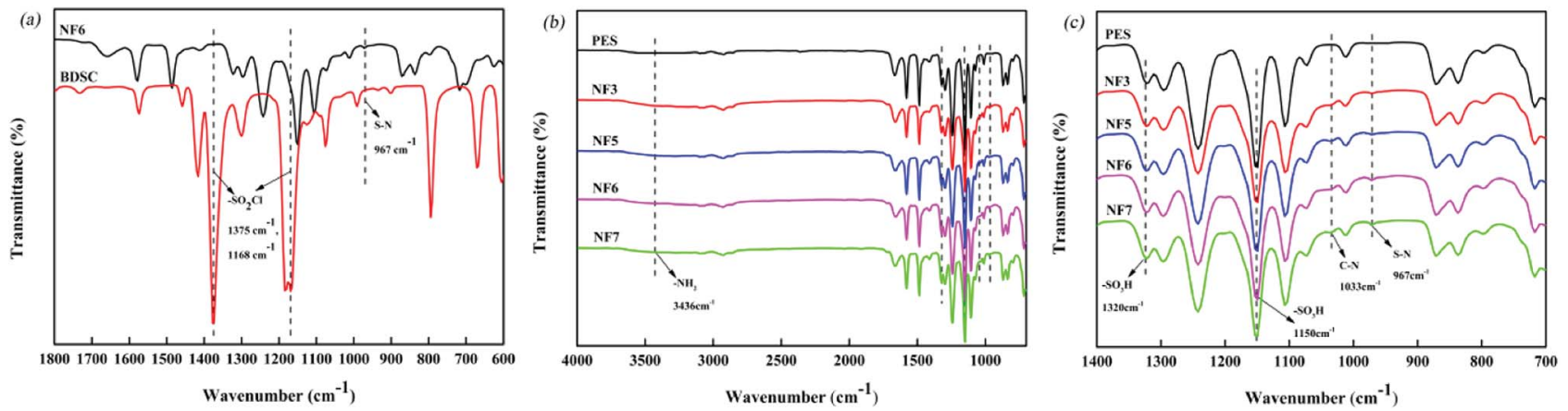

Fig. 4 ATR-FTIR spectra of (a) BDSC and the NF6 membrane and (b) the PES substrate and PSA composite membranes (NF3, NF5, NF6, and NF7). (c) Partial magnified image of (b).

Table 2 Surface atomic contents of PES substrate and NF3 and NF6 membranes

\begin{tabular}{llllll}
\hline Membrane & $\mathrm{C}(\%)$ & $\mathrm{O}(\%)$ & $\mathrm{N}(\%)$ & $\mathrm{S}(\%)$ & $\mathrm{S} / \mathrm{N}$ \\
\hline PES & 74.38 & 20.51 & 0 & 4.92 & - \\
NF3 & 69.64 & 15.73 & 9.92 & 4.7 & 0.47 \\
NF6 & 64.79 & 20.09 & 9.32 & 5.8 & 0.62
\end{tabular}

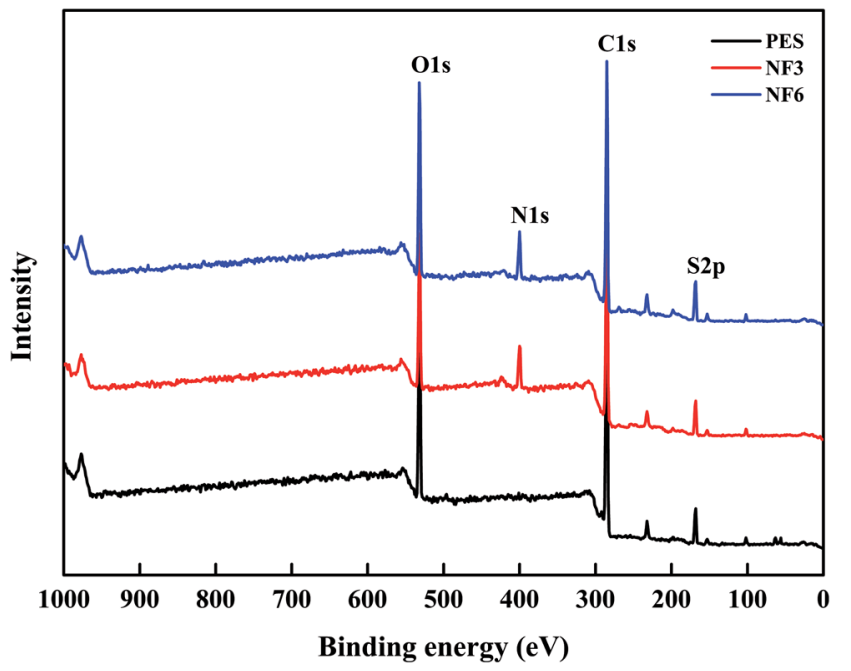

Fig. 5 XPS spectra of the PES substrate and the surfaces of the NF3 and NF6 membranes.

the $\mathrm{MgCl}_{2}$ rejection decreased to $53.0 \%$. Therefore, according to the above results for the separation performance, we fixed the concentration of the PAH aqueous solution at $0.7 \%(\mathrm{w} / \mathrm{v})$ and then changed the BDSC concentration to investigate its effect on the performance of the PSA composite membrane. With an increase in the BDSC concentration from $0.02 \%$ to $0.1 \%(\mathrm{w} / \mathrm{v})$, the permeation flux decreased quickly from 42.2 to $34.1 \mathrm{~L} \mathrm{~m}^{-2} \mathrm{~h}^{-1}$ and the $\mathrm{MgCl}_{2}$ rejection increased from $72.5 \%$ to $92.4 \%$. As the BDSC concentration was further increased to $0.14 \%(\mathrm{w} / \mathrm{v})$, it had less effect on the separation performance of the membrane. This result corresponds to a typical property of organic monomers reported in the literature, ${ }^{45,46}$ whereby an increase in the concentration of an organic monomer will increase the degree of IP. This results in a compact and thick PSA active separation layer on the PES substrate, so that the PSA composite membrane that is obtained exhibits a low permeation flux and a high salt rejection. When the PAH concentration was low, and with an increase in the PAH concentration, the permeation flux of the PSA composite membrane decreased and the $\mathrm{MgCl}_{2}$ rejection increased. This result is consistent with the effect of increasing the BDSC concentration. However, when the PAH concentration was further increased, the permeation flux of the PSA composite membrane increased, whereas the $\mathrm{MgCl}_{2}$ rejection was sharply reduced. This result is most likely to be attributable to the macromolecular nature of $\mathrm{PAH}$, which, as a polymer, does not easily diffuse into the organic phase to react with BDSC in comparison with small molecules. Therefore, the BDSC monomer diffused into the aqueous phase to react with $\mathrm{PAH}$. When the $\mathrm{PAH}$ concentration was high, more amine groups from macromolecular $\mathrm{PAH}$ were present on the PES substrate and the supply of BDSC was in deficit. In this case, the PSA active separation layer was loose and a membrane with a high permeation flux and a low rejection was produced.

Here, we also studied the effect of the reaction monomer concentration on the hydrophilicity of the PSA membrane surface. It is well known that the surface hydrophilicity plays an important role in the permeation flux of a membrane. The water contact angle is a critical parameter for determining the surface hydrophilicity of a membrane. ${ }^{48,49}$ In general, a low contact angle indicates that the hydrophilicity of the membrane surface is high, which is beneficial for increasing the permeation flux of the membrane. As shown in Table 1, we found that the water contact angle of the PSA membrane increased slightly with an increase in the $\mathrm{PAH}$ concentration from $0.1 \%$ to $1 \%(\mathrm{w} / \mathrm{v})$ at a fixed BDSC concentration of $0.02 \%(\mathrm{w} / \mathrm{v})$ in Isopar $\mathrm{G}$ solutions. However, at a fixed $\mathrm{PAH}$ concentration of $0.7 \%(\mathrm{w} / \mathrm{v})$ in aqueous solutions the water contact angle of the PSA membrane increased markedly from $83.1^{\circ}$ to $93.8^{\circ}$ with an increase in the BDSC concentration from $0.02 \%$ to $0.14 \%(\mathrm{w} / \mathrm{v})$, which indicated that the hydrophilicity of the membrane surface decreased significantly. Therefore, an increase in the BDSC content in the IP process had a greater effect on the surface hydrophilicity of the PSA membrane than that of PAH. 


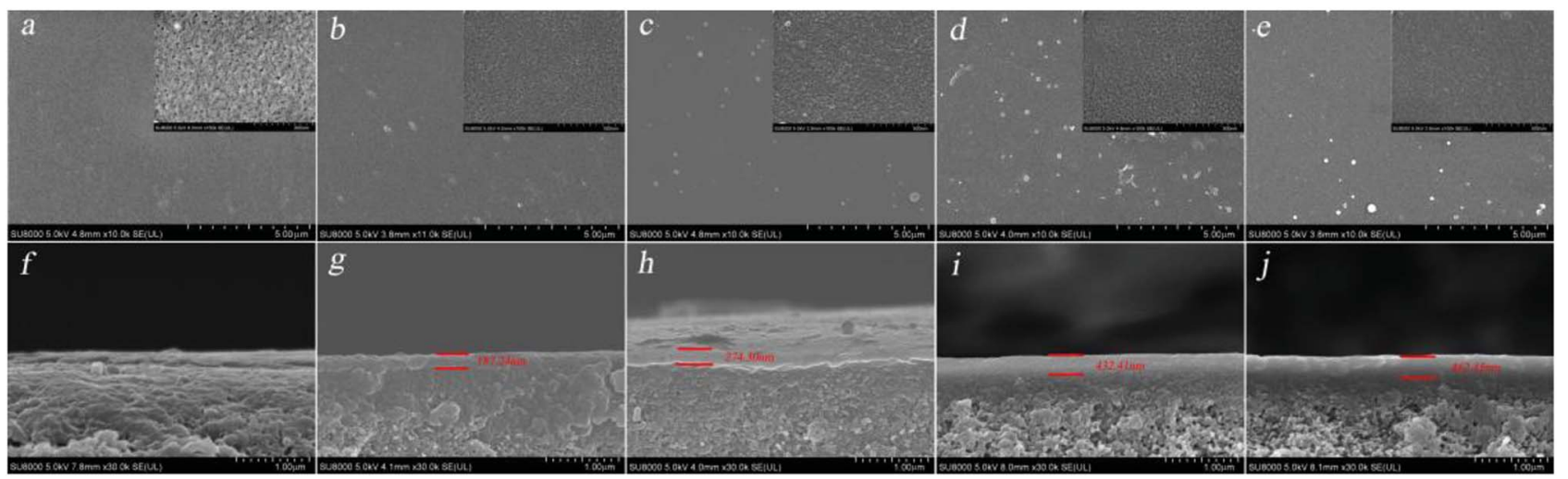

Fig. 6 SEM images (a, b, c, d, and e) show the surfaces of PES and the NF3, NF5, NF6, and NF7 membranes, respectively. Images (f, g, h, i, and j) show cross-sections of PES and the NF3, NF5, NF6, and NF7 membranes, respectively.

According to the above experimental results, the optimum polymerization conditions are: $\mathrm{PAH}$ concentration of $0.7 \%(\mathrm{w} /$ $\mathrm{v}), \mathrm{pH}$ of the PAH aqueous solution of 9.33, BDSC concentration of $0.1 \%(\mathrm{w} / \mathrm{v})$, soaking time in the $\mathrm{PAH}$ aqueous solution of $25 \mathrm{~min}$, and reaction time of $20 \mathrm{~min}$.

\subsection{Characterization of PSA composite membrane}

3.2.1 ATR-FTIR and XPS. The chemical structures produced between PAH and BDSC to form the PSA composite membrane were investigated by ATR-FTIR and XPS. Fig. 4 shows the ATR-FTIR spectra of the PES substrate and PSA composite membranes, which indicate that the PSA active separation layer was formed on the PES substrate. This is demonstrated by the absence of the sulfonyl chloride peaks at $1375 \mathrm{~cm}^{-1}$ and $1168 \mathrm{~cm}^{-1}$ and the appearance of an S-N peak due to sulfonamides at $967 \mathrm{~cm}^{-1}$ (ref. 31) (Fig. 4(a)). Fig. 4(b) shows the peaks at $3436 \mathrm{~cm}^{-1}$ (N-H stretching vibrations) and $1033 \mathrm{~cm}^{-1}$ (C-N stretching vibrations) due to the PAH amine groups. ${ }^{47}$ Moreover, the bands at $1320 \mathrm{~cm}^{-1}$ and $1150 \mathrm{~cm}^{-1}$ are attributed to the asymmetric and symmetric stretching modes of $-\mathrm{SO}_{3} \mathrm{H}$ groups in the PES substrate and PSA active separation layer, respectively, ${ }^{31,39}$ and the relative intensity of the peaks due to $-\mathrm{SO}_{3} \mathrm{H}$ groups slowly increased when the concentration of the BDSC solution was increased (Fig. 4(c)). The results indicated that more sulfonyl chloride groups were hydrolyzed to form sulfonic acid groups with an increase in the sulfonyl chloride concentration in the IP process. Finally, we also found that the relative intensity of the peaks due to $\mathrm{S}-\mathrm{N}$ groups increased when the BDSC concentration was increased (Fig. 4(c)). In addition, the chemical composition of the membrane surface with a depth of $10 \mathrm{~nm}$ was determined by XPS. As shown in Table 2 and Fig. 5, the surface sulfur (S) content of the PES substrate was $4.92 \%$, whereas the surface sulfur (S) content of the NF3 membrane was $4.7 \%$ and its nitrogen $(\mathrm{N})$ content was $9.92 \%$, which indicated the formation of the PSA active separation layer on the surface of the PES substrate. When we increased the concentration of the BDSC solution to prepare the NF6 membrane, the $\mathrm{S}$ content increased from $4.7 \%$ to $5.8 \%$ and the $\mathrm{N}$ content decreased from $9.92 \%$ to $9.32 \%$. Moreover, in terms of the $\mathrm{S} / \mathrm{N}$ ratio of the membrane surface, NF6 $>$ NF3. These results could be explained by the fact that increasing the concentration of the BDSC solution increased the extent of the IP reaction.
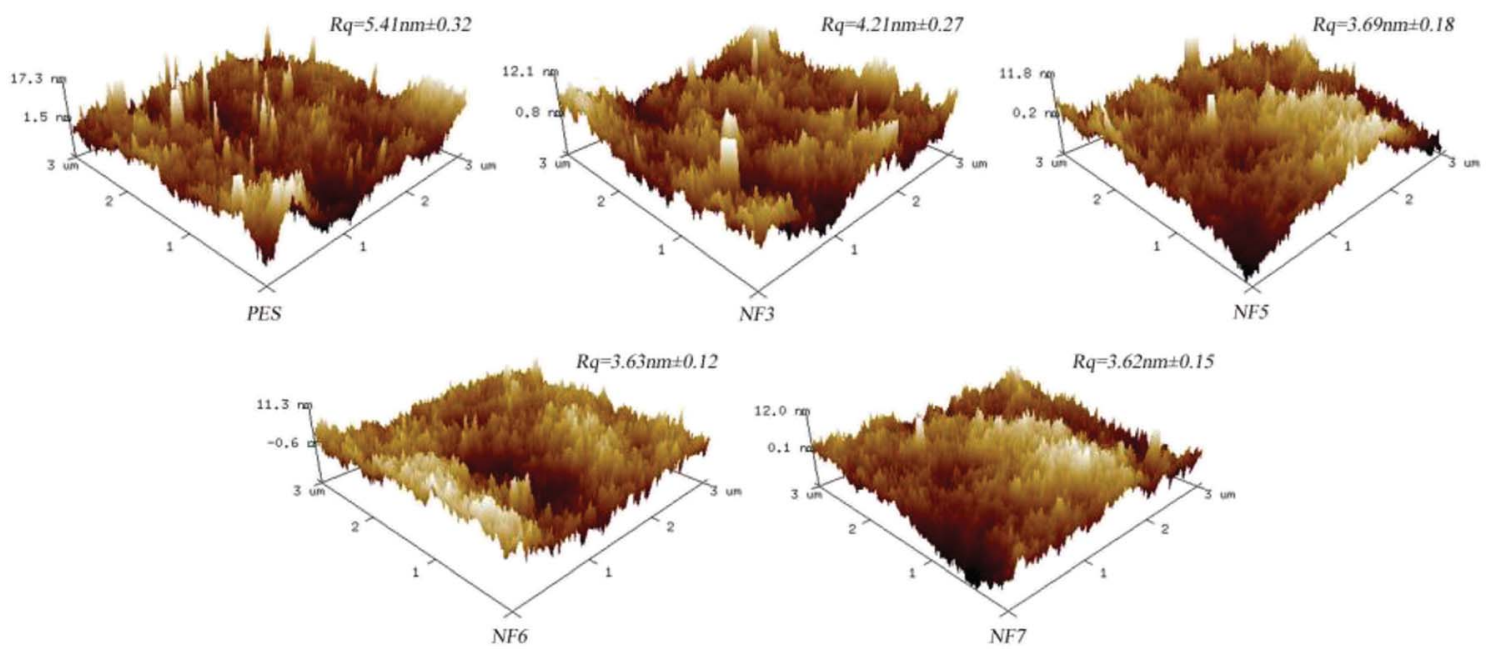

Fig. 7 Surface roughness images of the PES membrane support and NF3, NF5, NF6, and NF7 membranes. 
3.2.2 SEM and AFM. The surface and cross-section morphologies and surface roughness of the PSA composite membrane were investigated by SEM and AFM, respectively. Fig. 6 shows SEM images of the PSA composite membrane. It can be clearly observed that the PSA composite membrane, when compared with the PES substrate, displayed obvious changes in the surface and cross-section of the membrane, which indicated that the PSA active separation layer was present on the PES membrane support. It was also obvious that the thickness of the PSA active separation layer in the NF3, NF5, and NF6 membranes increased quickly from $187.24 \mathrm{~nm}$ to $432.41 \mathrm{~nm}$, and some bumps appeared on the membrane surface when the BDSC concentration was increased. However, the thickness of the NF6 and NF7 membranes increased slowly from 432.41 to $462.45 \mathrm{~nm}$, and no obvious change was observed in the membrane surface as the BDSC concentration was further increased. This result can be explained by the fact that increasing the extent of IP enhanced the compactness and thickness of the active separation layer when the monomer concentration was increased. In addition, because the growth of the IP active separation layer was self-limited, the thickness stopped increasing when the active separation layer being formed was thick enough to hinder diffusion of the monomer from one phase into another phase. Fig. 7 shows AFM images of the surface root mean square roughness (Rq) of the PES substrate and PSA composite membranes. The surface Rq of the PSA composite membrane when compared with that of the PES substrate clearly decreased, which indicated the formation of the PSA active separation layer on the PES substrate. Moreover, the surface Rq of the NF3, NF5, and NF6 membranes decreased from 4.21 to $3.63 \mathrm{~nm}$ with an increase in the concentration of the organic monomer. However, with a further increase in the organic monomer concentration, the surface $\mathrm{Rq}$ of the membrane was little changed. The result, i.e., a smooth PSA composite membrane, could be explained by the fact that the macromolecule PAH was deposited on the surface of the PES substrate to form a PAH top layer, which had a uniform

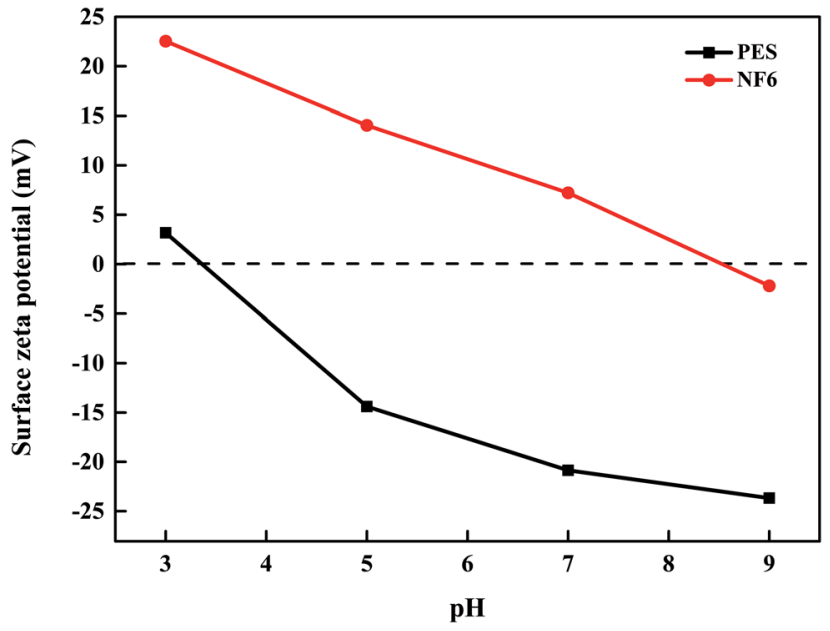

Fig. 8 Surface zeta potentials of the PES substrate and NF6 membrane

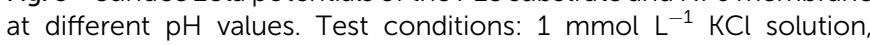
$25.0^{\circ} \mathrm{C}$.

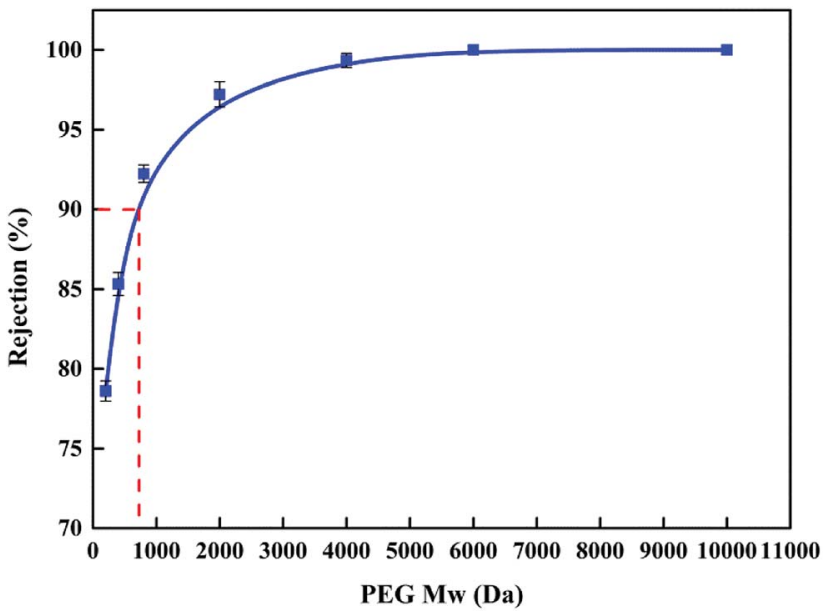

Fig. 9 PEG rejection curve for the NF6 membrane tested with a $50 \mathrm{mg} \mathrm{L}^{-1} \mathrm{PEG}$ solution at $0.5 \mathrm{MPa}$ and room temperature.

distribution of amine groups along the PAH chains, and thus the BDSC monomer diffused into the aqueous phase and reacted uniformly with PAH on the surface of the substrate, which resulted in the formation of a smooth active separation layer.

3.2.3 Zeta potential and MWCO. In the investigation of the zeta potential and MWCO, we chose the NF6 membrane prepared under the optimum polymerization conditions as the object of study. Fig. 8 shows the surface zeta potentials determined for the NF6 membrane and the PES substrate over the $\mathrm{pH}$ range of 3.0-9.0 by measurements of the streaming potential. It can clearly be observed that the isoelectric point (IEP) of the NF6 membrane was at a $\mathrm{pH}$ of about 8.5 ; this result indicated that the surface of the membrane was more positively charged in comparison with those of reported PSA composite membranes (IEP at a $\mathrm{pH}$ of about $3-5) .^{30,31}$ The strong positive charge was due to the fact that the surface of the NF6 membrane contained some unreacted $-\mathrm{NH}_{2}$ groups from $\mathrm{PAH}$ and $-\mathrm{SO}_{3} \mathrm{H}$ groups from the hydrolysis of the sulfonyl chloride, which could cause protonation with positive charges when the $\mathrm{pH}$ falls below the IEP. In addition, the $-\mathrm{NH}_{2}$ and $-\mathrm{SO}_{3} \mathrm{H}$ groups were deprotonated when the $\mathrm{pH}$ exceeded the IEP, and thereby the surface of the NF6 membrane was negatively charged. Thus, the newly

Table 3 Ion valences, diffusion coefficients and hydrated radius (at $\left.25^{\circ} \mathrm{C}\right) .44,50,51$

\begin{tabular}{lll}
\hline Ion & $\begin{array}{l}\text { Hydrated radius } \\
(\mathrm{nm})\end{array}$ & $\begin{array}{l}\text { Diffusion coefficient } \\
\left(10^{-9} \mathrm{~m}^{2} \mathrm{~s}^{-1}\right)\end{array}$ \\
\hline $\mathrm{H}_{3} \mathrm{O}^{+}$ & 0.280 & \\
$\mathrm{Mg}^{2+}$ & 0.428 & 9.31 \\
$\mathrm{Na}^{+}$ & 0.358 & 0.72 \\
$\mathrm{Zn}^{2+}$ & 0.430 & 1.334 \\
$\mathrm{Cd}^{2+}$ & 0.426 & 0.71 \\
$\mathrm{Cu}^{2+}$ & 0.419 & 0.87 \\
$\mathrm{~Pb}^{2+}$ & 0.401 & 0.72 \\
$\mathrm{SO}_{4}{ }^{2-}$ & 0.379 & 0.95 \\
$\mathrm{NO}_{3}{ }^{-}$ & 0.335 & 1.065 \\
$\mathrm{Cl}^{-}$ & 0.332 & 1.292
\end{tabular}




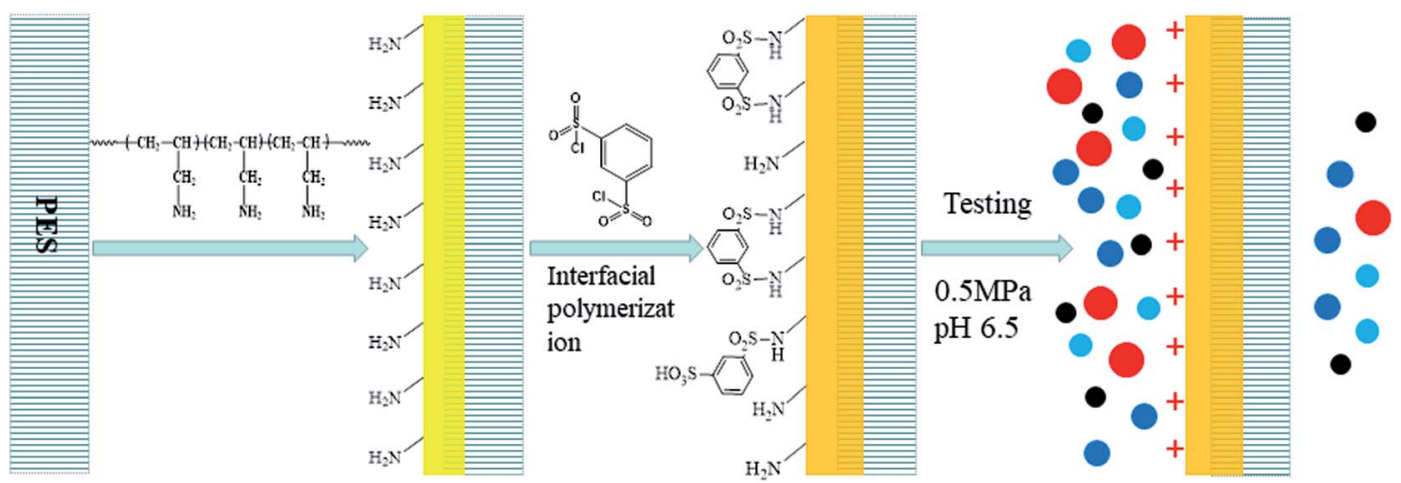

\section{$\mathrm{Mg}^{2+} \bigcirc \mathrm{Na}^{+} \bigcirc \mathrm{SO}_{4}^{2-} \odot \mathrm{Cl}^{-}$}

Scheme 2 Schematic diagram of separation process of inorganic salts using the desired PSA membrane.

formed PSA membrane prepared from PAH and BDSC has a strong positive charge, which has obvious advantages for rejecting bivalent metal ions according to the Donnan effect.

The MWCO of the NF6 membrane was determined by testing using PEG with molecular weights of 200, 400, 800, 2000, 4000, 6000 , and $10000 \mathrm{Da}$. The experimental results are shown in Fig. 9. It can be observed that the MWCO of the NF6 membrane was about $720 \mathrm{Da}$. The pore radius of the membrane was $0.73 \mathrm{~nm}$ according to DSPM calculations. By comparison with the MWCO (6000 Da) of a reported PSA composite membrane, ${ }^{31}$ the newly formed PSA membrane was more compact. This result, i.e., the compactness of the PSA composite membrane, can be explained by the fact that in the process of immersion in the aqueous phase the macromolecule PAH diffused into pores in the PES substrate and was deposited on its surface to form a PAH top layer. The top layer provided sufficient amine groups to react with BDSC to form the PSA active layer, and thus the surface of the PES substrate was covered by the active layer, which reduced the number and size of surface pores. Similar results have been reported..$^{6,25,44,50-52}$

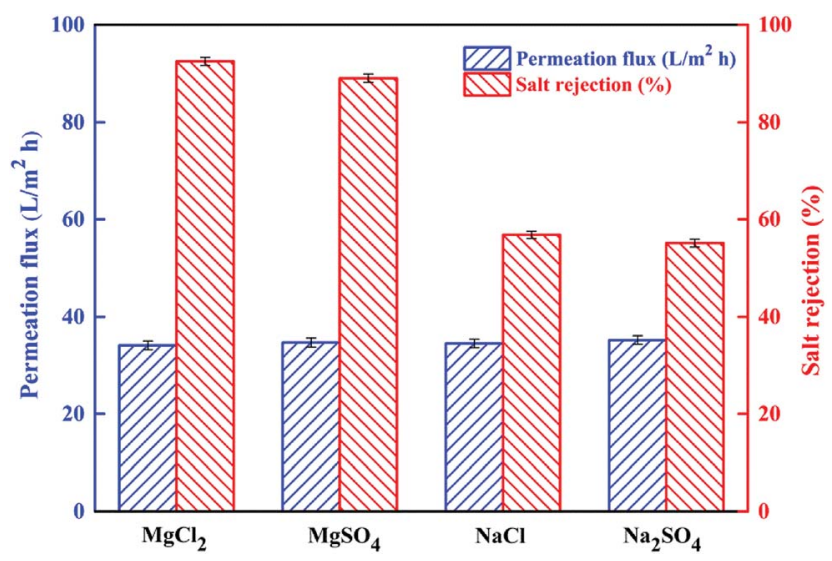

Fig. 10 Rejection of different salts and permeation flux of the NF6 membrane determined with $1 \mathrm{~g} \mathrm{~L}^{-1}$ salt solutions at $0.5 \mathrm{MPa}$, a $\mathrm{pH}$ of 6.5 , and room temperature.
On the basis of the above results, the new PSA composite membrane is positively charged and has a pore radius of $0.73 \mathrm{~nm}$. It is a typical NF membrane with positive charge. The separation mechanisms of NF membranes include the Donnan effect and pore size sieving. However, the pore radius of the PSA composite membrane is larger than the radius of some hydrated ions (Table 3), and therefore the Donnan effect plays the main role in the process of separation. Scheme 2 is a schematic diagram of the separation process of inorganic salts using the desired PSA membrane, which shows that the surface of the PSA composite membrane has a strong positive charge at a $\mathrm{pH}$ of around 6.5. Thus, the new PSA composite membrane can achieve the selective separation of different ions and exhibit excellent rejection of divalent metal ions.

\subsection{Evaluation of performance of PSA composite membrane}

Next, the NF6 membrane prepared under the optimum polymerization conditions was selected as the object of further study of the performance of the membrane.

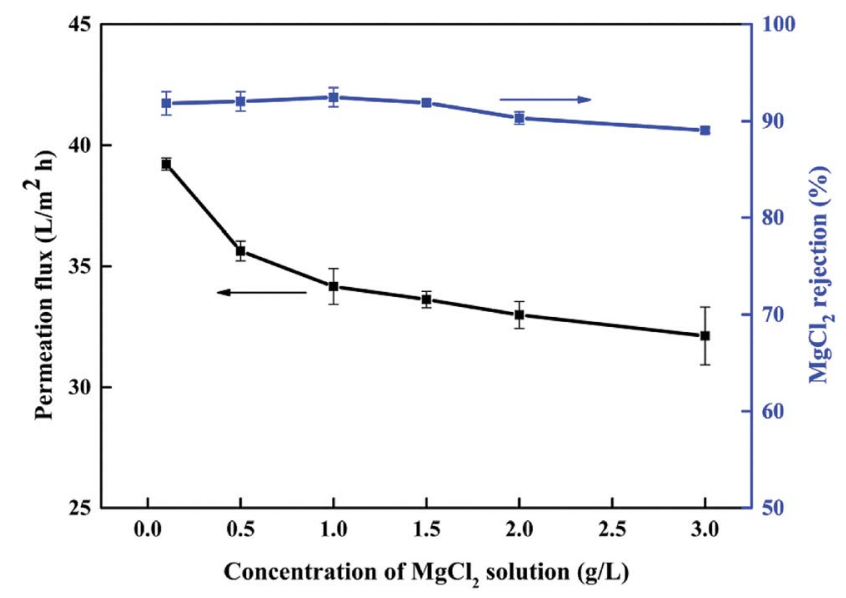

Fig. 11 Effect of concentration of $\mathrm{MgCl}_{2}$ feed solution on performance of NF6 membrane. Test conditions: $0.5 \mathrm{MPa}, \mathrm{pH} 6.5$, room temperature. 


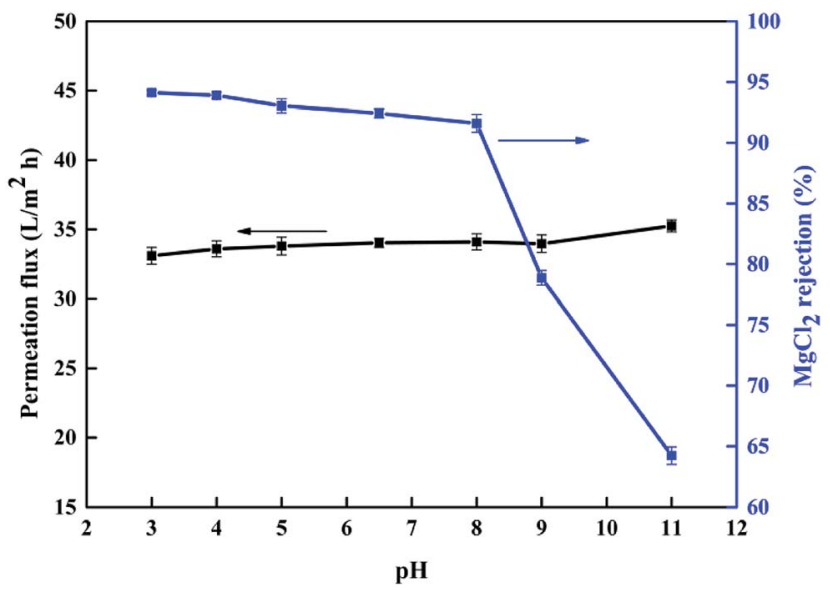

Fig. 12 Effect of $\mathrm{pH}$ of $\mathrm{MgCl}_{2}$ feed solution on separation performance of NF6 membrane. Test conditions: $\mathrm{MgCl}_{2}$ concentration $1 \mathrm{~g}$ $\mathrm{L}^{-1}, 0.5 \mathrm{MPa}, \mathrm{pH} 6.5$, room temperature.

3.3.1 Separation performance of PSA composite membrane. Fig. 10 shows the rejection of four inorganic salts by the NF6 membrane, namely, $\mathrm{MgCl}_{2}(92.44 \%)>\mathrm{MgSO}_{4}(88.9 \%)>$ $\mathrm{NaCl}(56.8 \%)>\mathrm{Na}_{2} \mathrm{SO}_{4}(55.2 \%)$, although the permeation flux did not change markedly. This result indicated that the surface of the NF6 membrane was positively charged, which is consistent with the results presented in the form of the zeta potential data. Here, the Donnan effect played the main role in the process of separation. This effect is related to the charge properties of the membrane surface, the ion valence, and the diffusion coefficient. ${ }^{24,51}$ Therefore, the NF membrane with positive charge had a higher rejection of divalent cations $\left(\mathrm{Mg}^{2+}\right)$

Table 4 Separation performance of the NF6 membrane for heavy metal salts. Test conditions: salt concentrations of $1 \mathrm{~g} \mathrm{~L}^{-1}, 0.5 \mathrm{MPa}$, room temperature

\begin{tabular}{lll}
\hline Salt & Rejection (\%) & $\begin{array}{l}\text { Permeation flux } \\
\left.(\mathrm{L} \mathrm{m})^{-2} \mathrm{~h}^{-1}\right)\end{array}$ \\
\hline $\mathrm{ZnCl}_{2}$ & $95.23 \pm 0.58$ & $33.70 \pm 0.6$ \\
$\mathrm{CuCl}_{2}$ & $93.42 \pm 0.68$ & $33.90 \pm 0.79$ \\
$\mathrm{CdCl}_{2}$ & $91.20 \pm 0.49$ & $34.13 \pm 0.6$ \\
$\mathrm{~Pb}\left(\mathrm{NO}_{3}\right)_{2}$ & $92.11 \pm 0.55$ & $34.36 \pm 0.71$
\end{tabular}

than of monovalent cations $\left(\mathrm{Na}^{+}\right)$. In the case of anions, monovalent anions $\left(\mathrm{Cl}^{-}\right)$have higher diffusion coefficients when compared with divalent anions $\left(\mathrm{SO}_{4}{ }^{2-}\right)$, but $\mathrm{SO}_{4}{ }^{2-}$ ions have a higher negative charge, and hence the rejection of $\mathrm{SO}_{4}{ }^{2-}$ ions was reduced. In addition, the selective rejection of different inorganic salts by the PSA composite membrane is consistent with Scheme 2 .

3.3.2 Effect of $\mathbf{p H}$ and concentration of feed solution on membrane performance. It has been reported that the performance of $\mathrm{NF}$ membranes is easily affected by the $\mathrm{pH}$ or concentration of the feed solution in industrial production. ${ }^{\mathbf{2 3 2 4 , 5 1}}$ Hence, it is necessary to systematically study these factors.

Firstly, we selected $\mathrm{MgCl}_{2}$ solutions with concentrations of 0.1-3 $\mathrm{g} \mathrm{L}^{-1}$ to study how the feed concentration affected the separation performance of the NF6 membrane. The experimental results are shown in Fig. 11. In the case of the $\mathrm{MgCl}_{2}$ solutions, the rejection and permeation flux of the NF6 membrane declined to a lesser extent with an increase in the feed concentration. The rejection results can be explained by the Donnan effect. ${ }^{23}$ The Donnan effect of the NF membrane on the ions decreased when the feed concentration increased, which resulted in a decline in the rejection of $\mathrm{MgCl}_{2}$. The decrease in the permeation flux was due to the increase in the $\mathrm{MgCl}_{2}$ concentration, which made the osmotic pressure $(\pi)$ increase on both sides of the membrane and thereby reduced the effective pressure $(\Delta P)$ according to eqn (1)-(3). The experimental results indicated that the performance of the new PSA composite membrane is stable and little affected by the concentration of inorganic salts.

Next, the effects of different $\mathrm{pH}$ values of the feed solution on the performance of the NF6 membrane were also investigated. Fig. 12 shows the results of this experiment. It is clearly seen that the rejection of $\mathrm{MgCl}_{2}$ by the NF6 membrane gradually increased from $91.6 \%$ to $94.2 \%$ when the feed $\mathrm{pH}$ was decreased from 8 to 3 . With an increase in the $\mathrm{pH}$ from 8 to 11, the rejection of $\mathrm{MgCl}_{2}$ decreased rapidly from $91.6 \%$ to $64.2 \%$. This result can be explained by noting that more $-\mathrm{NH}_{2}$ groups can be protonated on the surface of the NF6 membrane at a low $\mathrm{pH}$ and thus make the membrane surface more positively charged, which enhances the rejection of $\mathrm{Mg}^{2+}$. When the $\mathrm{pH}$ exceeds the IEP, the positively charged surface of the membrane becomes

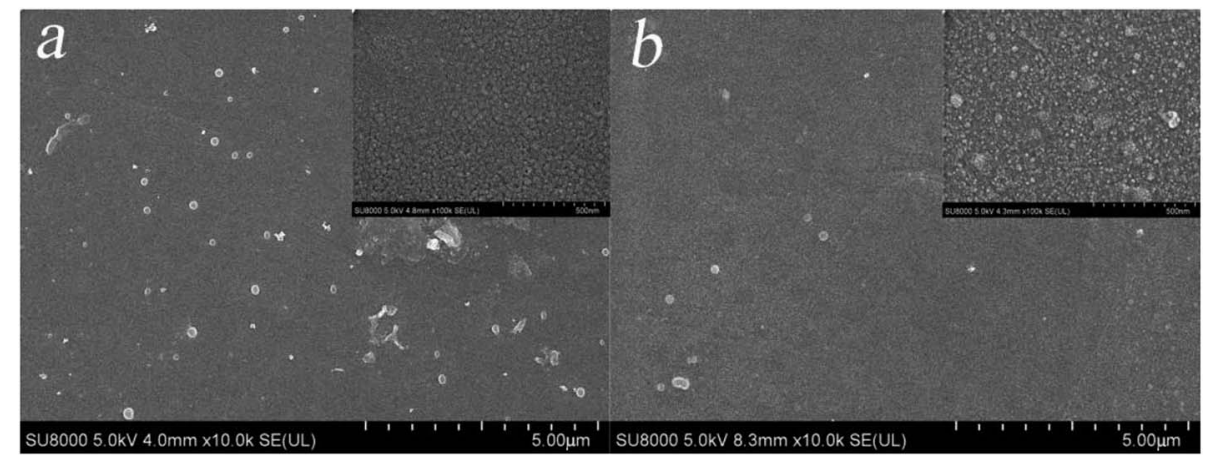

Fig. 13 SEM images of (a) the NF6 membrane surface and (b) the NF6 membrane surface after exposure to an acidic solution for 30 days. 
negatively charged and thereby the rejection of $\mathrm{Mg}^{2+}$ decreases. However, the permeation flux of the NF6 membrane did not change significantly (Fig. 12), which indicated that the structure of the surface of the NF6 membrane was stable at pH values in the range from 3 to 11 . The experimental results show that the new PSA composite membrane is suited to the treatment of inorganic salts in acidic environments.

3.3.3 Separation of heavy metal ions. Heavy metal ions are toxic substances in industrial wastewater and are not easily degraded, and hence the removal of heavy metal ions is an urgent problem. Next, we studied the application of the NF6 membrane in the separation of heavy metal ions. Table 4 shows the separation performance of the NF6 membrane for heavy metal salts, namely, $\mathrm{ZnCl}_{2}, \mathrm{CuCl}_{2}, \mathrm{~Pb}\left(\mathrm{NO}_{3}\right)_{2}$, and $\mathrm{CdCl}_{2}$. The rejection of the heavy metal salts increased in the following order: $\mathrm{CdCl}_{2}<\mathrm{Pb}\left(\mathrm{NO}_{3}\right)_{2}<\mathrm{CuCl}_{2}<\mathrm{ZnCl}_{2}$. We can determine that the surface of the NF6 membrane was positively charged and mainly relied on the Donnan effect to reject the metal ions. This was related to the valence state and diffusion coefficient of the metal ions. For cations with the same valence $\left(\mathrm{Zn}^{2+}, \mathrm{Cu}^{2+}, \mathrm{Pb}^{2+}\right.$ and $\mathrm{Cd}^{2+}$ ), the rejection order was determined by the diffusion coefficients listed in Table 4. Heavy metal ions with lower diffusion coefficients had more difficulty in permeating through the membrane and thereby had higher rejections. The rejection of $\mathrm{Pb}^{2+}$ was mainly determined by the diffusion coefficient of $\mathrm{NO}_{3}{ }^{-}$, which is lower than the diffusion coefficient of $\mathrm{Cl}^{-}$. This experimental result shows that the new PSA composite membrane has an excellent separation effect for heavy metal ions, with a rejection of greater than $90 \%$ and a high permeation flux of up to $34 \mathrm{~L} \mathrm{~m}^{-2} \mathrm{~h}^{-1}$, which is suitable for the treatment of heavy metal ions.

3.3.4 Acid stability of the membrane. Next, we studied the acid stability of the prepared PSA composite membrane by exposing it to a $20.0 \%(\mathrm{w} / \mathrm{v}) \mathrm{H}_{2} \mathrm{SO}_{4}$ solution for fixed periods. The surface of the NF6 membrane was investigated using SEM before and after exposure to the acidic solution for 30 days. Fig. 13 shows the resulting SEM image. The surface of the NF6

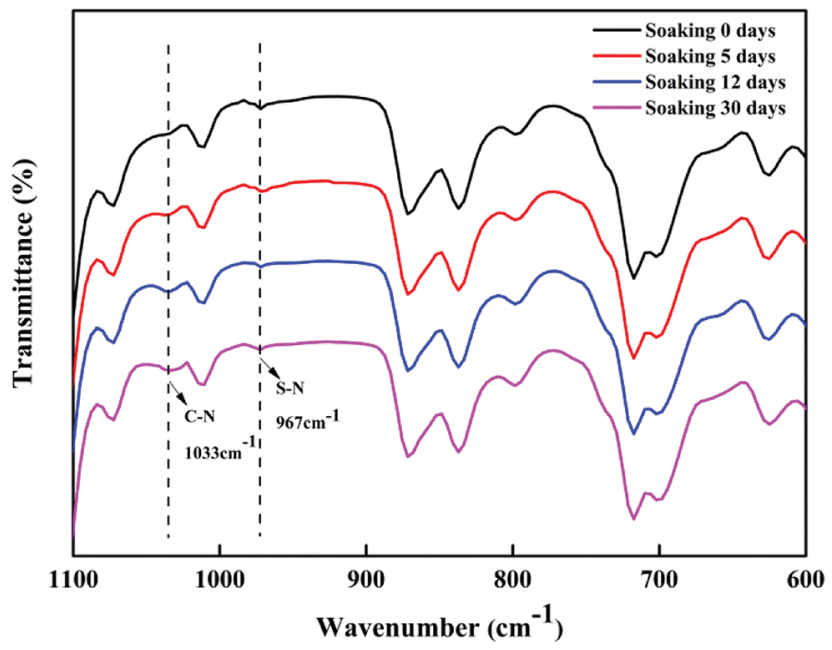

Fig. 14 ATR-FTIR spectra of the NF6 membrane after exposure to an acidic solution for $0,5,12$, and 30 days.

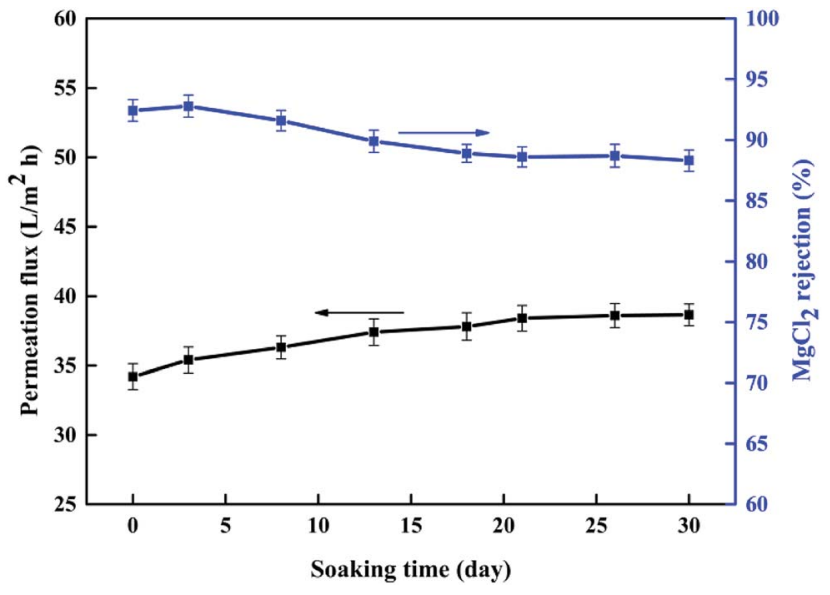

Fig. 15 The separation performance of the NF6 membrane after exposure to a $20 \%(\mathrm{w} / \mathrm{v}) \mathrm{H}_{2} \mathrm{SO}_{4}$ solution for a fixed period was evaluated with a $1 \mathrm{~g} \mathrm{~L}^{-1} \mathrm{MgCl}_{2}$ solution at $0.5 \mathrm{MPa}$, a pH of 6.5 , and room temperature.

membrane had no obvious cracks after exposure to the acid solution. The ATR-FTIR spectra of the NF6 membrane after exposure to the acidic solution for $0,5,12$, and 30 days are shown in Fig. 14. It can clearly be seen that the peak at $967 \mathrm{~cm}^{-1}$ due to $\mathrm{S}-\mathrm{N}$ groups was still present at all these time points. Fig. 15 shows the separation performance of the NF6 membrane after exposure to the acidic solution for a fixed period. It was seen that the $\mathrm{MgCl}_{2}$ rejection decreased from $92.40 \%$ to $88.30 \%$ and the corresponding permeation flux increased from $34.10 \mathrm{~L}$ $\mathrm{m}^{-2} \mathrm{~h}^{-1}$ to $38.60 \mathrm{~L} \mathrm{~m}^{-2} \mathrm{~h}^{-1}$. The change in the performance of the NF6 membrane was slow. These results indicated that the PSA composite membranes have excellent acid stability, which was attributed to the stable chemical structure of the sulfonamide bond. According to our analysis of the sulfonamide structure, the acid stability is explained by the steric effect and electronic effect. $^{39}$ Scheme 3 shows a schematic diagram explaining the acid stability of the sulfonamide structure:

(1) Steric effect: Scheme 3(1) shows that all the bond angles in the sulfonamide group are about $109.5^{\circ}$, which causes a nucleophile that attacks the sulfur atom to suffer more steric hindrance.

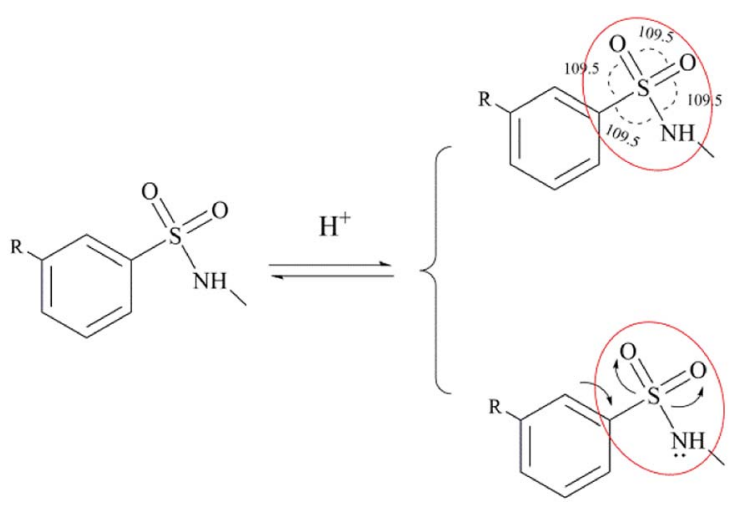

Scheme 3 Schematic diagram explaining the acid stability of the sulfonamide structure: (1) steric effect, (2) electronic effect. 
Table 5 Comparison of the separation performance of the PSA composite membrane prepared in this study with that of other acid-stable membranes

\begin{tabular}{|c|c|c|c|c|c|}
\hline Membrane material & $\begin{array}{l}\text { Salt rejection } \\
(\%)\end{array}$ & $\begin{array}{l}\text { Permeation flux } \\
\left(\mathrm{L} \mathrm{m}^{-2} \mathrm{~h}^{-1} \mathrm{bar}^{-1}\right)\end{array}$ & $\begin{array}{l}\text { Isoelectric point } \\
\text { (pH value) }\end{array}$ & Test conditions & Ref. \\
\hline Sulfonated polyetherketone & $85 \%^{a}$ & 0.8 & 2.5 & $1 \mathrm{M} \mathrm{HNO}_{3}, 25^{\circ} \mathrm{C}$, dead-end filtration setup & 37 \\
\hline Poly(s-triazine-amine) & $91 \%^{a}$ & $0.2-0.7$ & $\approx 7.8$ & $0.1 \mathrm{M} \mathrm{HNO}_{3}, 25^{\circ} \mathrm{C}$, dead-end filtration setup & 28 \\
\hline Poly(s-triazine-amine) & $85.2 \%^{b}$ & 1.5 & $\approx 7.8$ & $0.1 \mathrm{M} \mathrm{HNO}_{3}, 25{ }^{\circ} \mathrm{C}$, dead-end filtration setup & 29 \\
\hline Polysulfonamide (PIP-NTSC) & $42.5 \%^{a}$ & 6.5 & $\approx 3$ & $20.0 \%(\mathrm{w} / \mathrm{v}) \mathrm{H}_{2} \mathrm{SO}_{4}, 25{ }^{\circ} \mathrm{C}$, cross-flow filtration setup & 31 \\
\hline Polysulfonamide (PIP-BDSC) & $42 \%^{b}$ & $\approx 3$ & $\approx 3.5$ & $10.0 \%(\mathrm{w} / \mathrm{w}) \mathrm{H}_{2} \mathrm{SO}_{4}, 55^{\circ} \mathrm{C}$, cross-flow filtration setup & 39 \\
\hline Polysulfonamide (MPD-BDSC) & $25 \%^{b}$ & $\approx 2$ & $\approx 4.4$ & $10.0 \%(\mathrm{w} / \mathrm{w}) \mathrm{H}_{2} \mathrm{SO}_{4}, 55^{\circ} \mathrm{C}$, cross-flow filtration setup & 39 \\
\hline Polysulfonamide (PAH-BDSC) & $88.3 \%^{a}$ & 7.8 & 8.5 & $20.0 \%(\mathrm{w} / \mathrm{v}) \mathrm{H}_{2} \mathrm{SO}_{4}, 25{ }^{\circ} \mathrm{C}$, cross-flow filtration setup & This work \\
\hline
\end{tabular}

(2) Electronic effect: Scheme 3(2) shows that the sulfuroxygen double bonds in the sulfonamide group together with the lone pair of electrons on the nitrogen atom form $P-\pi$ conjugated structures, which can reduce nucleophilic attack on the sulfur atom and thereby increase the stability of the S-N bond.

In addition, we analyzed statistics for the separation performance of some acid-stable membranes (Table 5). These show that the new PSA composite membrane has high acid stability and separation performance in comparison with other acid-stable membranes.

\section{Conclusions}

In this study, a high-performance PSA composite membrane with acid stability was fabricated by IP of macromolecular PAH and BDSC on a PES substrate. By tailoring the polymerization conditions, a smooth and more compact PSA active separation layer with an IEP at a pH of around 8.5, in contrast to those of reported PSA composite membranes, was obtained. The desired PSA membrane exhibited a high permeation flux of up to $34.10 \mathrm{~L} \mathrm{~m}^{-2} \mathrm{~h}^{-1}$ and a high rejection of a $1 \mathrm{~g} \mathrm{~L}^{-1} \mathrm{MgCl}_{2}$ solution of up to $92.44 \%$. In addition, the new PSA composite membrane was positively charged and exhibited excellent rejection of heavy metal ions (rejection $>90 \%$ ). Moreover, the PSA membrane also exhibited excellent acid stability in an acid stability test. No obvious changes in $\mathrm{MgCl}_{2}$ rejection and permeation flux were observed after exposure to a $20 \%(\mathrm{w} / \mathrm{v}) \mathrm{H}_{2} \mathrm{SO}_{4}$ solution for 30 days, which was attributed to the stable chemical structure of sulfonamide bonds. Therefore, the new PSA membranes exhibited potential for water desalination and the removal of heavy metal ions from an acidic environment.

\section{Conflicts of interest}

There are no conflicts to declare.

\section{Acknowledgements}

The financial support for this work was from the National Natural Science Foundation of China (No. 21464012), the Funds for Distinguished Young Scientists of Xinjiang Bingtuan (No.
2014CD001), the Program for Changjiang Scholars and Innovative Research Team in University (No. IRT_15R46) and the Bingtuan Innovation Team in Key Areas (2015BD003).

\section{References}

1 H. Z. Zhang, Z. L. Xu, H. Ding and Y. J. Tang, Desalination, 2017, 420, 158-166.

2 J. Kim, H. Kwon, S. Lee, S. Lee and S. Hong, Desalination, 2017, 403, 172-178.

3 A. Alkhudhiri, N. Darwish and N. Hilal, Desalination, 2013, 309, 46-51.

4 Y. S. Li, L. Yan, C. B. Xiang and L. J. Hong, Desalination, 2006, 196, 76-83.

5 G. S. Lai, W. J. Lau, P. S. Goh, A. F. Ismail, H. Y. Tan, Y. C. Chong, R. K. Rehberg and S. Awad, Chem. Eng. J., 2018, 344, 524-534.

6 Y. Zhang, Y. Su, J. Peng, X. Zhao, J. Liu, J. Zhao and Z. Jiang, J. Membr. Sci., 2013, 429, 235-242.

7 Z. Lv, J. Hu, J. Zheng, X. Zhang, J. Liu, J. Zhao and Z. Jiang, Ind. Eng. Chem. Res., 2016, 55, 4726-4733.

8 W. R. Bowen, A. W. Mohammad and N. Hilal, J. Membr. Sci., 1997, 126, 91-105.

9 X. L. Wang, T. Tsuru, S. I. Nakao and S. Kimura, J. Membr. Sci., 1997, 135, 19-32.

10 V. Silva, Á. Martín, F. Martínez, J. Malfeito, P. Prádanos, L. Palacio and A. Hernández, Chem. Eng. Sci., 2011, 66, 2898-2911.

11 A. A. Hussain, S. K. Nataraj, M. E. E. Abashar, I. S. A. Mutaz and T. M. Aminabhavi, J. Membr. Sci., 2008, 310, 321-336.

12 X. Jiang, S. Li, S. He, Y. Bai and L. Shao, J. Mater. Chem. A., 2018, 6, 15064-15073.

13 Y. L. Ji, Q. F. An, F. Y. Zhao and C. J. Gao, Desalination, 2015, 357, 8-15.

14 G. Liu, Z. Jiang, X. Cheng, C. Chen, H. Yang, H. Wu, F. Pan, P. Zhang and X. Cao, J. Membr. Sci., 2016, 520, 364-373.

15 H. Wang, C. Wu, Z. Wei, C. Li and Q. Liu, RSC Adv., 2016, 6, 4673-4682.

16 Y. Li, Y. Su, Y. Dong, X. Zhao, Z. Jiang, R. Zhang and J. Zhao, Desalination, 2014, 333, 59-65.

17 Y. J. Tang, Z. L. Xu, S. M. Xue, Y. M. Wei and H. A. Yang, J. Membr. Sci., 2016, 498, 374-384. 
18 B. W. Zhou, H. Z. Zhang, Z. L. Xu and Y. J. Tang, Desalination, 2016, 394, 176-184.

19 S. Xiong, D. Y. Zhang, S. Mei, J. Liu, Y. S. Shi and Y. Wang, J. Membr. Sci., 2018, 551, 294-304.

20 Y. C. Chiang, Y. Z. Hsub, R. C. Ruaan, C. J. Chuang and K. L. Tung, J. Membr. Sci., 2009, 326, 19-26.

21 A. A. Tashvigh and T. S. Chung, J. Membr. Sci., 2018, 560, 115-124.

22 J. Y. Sum, J. J. Beh, A. L. Ahmad and B. S. Ooi, J. Ind. Eng. Chem., 2018, 58, 229-239.

23 L. Li, B. Wang, H. Tan, T. Chen and J. Xu, J. Membr. Sci., 2006, 269, 84-93.

24 M. Liu, Y. Zheng, S. Shuai, Q. Zhou, S. Yu and C. Gao, Desalination, 2012, 288, 98-107.

25 S. Yu, M. Ma, J. Liu, J. Tao, M. Liu and C. Gao, J. Membr. Sci., 2011, 379, 164-173.

26 X. Q. Cheng, Y. Liu, Z. Guo and L. Shao, J. Membr. Sci., 2015, 493, 156-166.

27 X. Li, Y. Cao, H. Yu, G. Kang, X. Jie, Z. Liu and Q. Yuan, J. Membr. Sci., 2014, 466, 82-91.

28 K. P. Lee, G. Bargeman, R. D. Rooij, A. J. B. Kemperman and N. E. Benes, J. Membr. Sci., 2017, 523, 487-496.

29 K. P. Lee, J. Zheng, G. Bargeman, A. J. B. Kemperman and N. E. Benes, J. Membr. Sci., 2015, 478, 75-84.

30 J. P. Soulier, B. Chabert, J. Chauchard, P. Berticat and J. F. May, J. Appl. Polym. Sci., 1974, 18, 2435-2447.

31 M. Liu, G. Yao, Q. Cheng, M. Ma, S. Yu and C. Gao, J. Membr. Sci., 2012, 415, 122-131.

32 D. Jakobs and G. Baumgarten, Desalination, 2002, 145, 6568.

33 M. P. Gonzalez, R. Navarro, I. Saucedo, M. Avila, J. Revilla and C. Bouchard, Desalination, 2002, 147, 315-320.

34 M. C. M. Calatayud, D. C. Buzzi, M. G. Gabaldon, E. Ortega, A. M. Bernardes, J. A. S. Tenorio and V. P. Herranz, Desalination, 2014, 343, 120-127.

35 Y. Nleya, G. S. Simate and S. Ndlovu, J. Cleaner Prod., 2016, 113, 17-27.
36 F. T. Awadalla, C. Striez and K. Lamb, Sep. Sci. Technol., 1994, 29, 483-495.

37 M. Dalwani, G. Bargeman, S. S. Hosseiny, M. Boerrigter, M. Wessling and N. E. Benes, J. Membr. Sci., 2011, 381, 8189.

38 S. Guan, S. Zhang, P. Liu, G. Zhang and X. Jian, Appl. Surf. Sci., 2014, 295, 130-136.

39 H. Hoseinpour, M. Peyravi, A. Nozad and M. Jahanshahi, J. Taiwan Inst. Chem. Eng., 2016, 67, 453-466.

40 B. J. Trushinski, J. M. Dickson, T. Smyth, R. F. Childs and B. E. McCarry, J. Membr. Sci., 1998, 143, 181-188.

41 H. Hoseinpour, M. Jahanshahi, M. Peyravi and A. Nozad, J. Ind. Eng. Chem., 2017, 46, 244-257.

42 A. D. Sabde, M. K. Trivedi, V. Ramachandhran, M. S. Hanra and B. M. Misra, Desalination, 1997, 114, 223-232.

43 A. K. Ghosh, B. H. Jeong, X. Huang and E. M. V. Hoek, J. Membr. Sci., 2008, 311, 34-45.

44 W. Fang, L. Shi and R. Wang, J. Membr. Sci., 2013, 430, 129139.

45 L. Setiawan, L. Shi and R. Wang, Polymer, 2014, 55, 13671374.

46 F. Yang, S. Zhang, D. Yang and X. Jian, J. Membr. Sci., 2007, 301, 85-92.

47 J. J. Richardson, B. L. Tardy, H. Ejima, J. Guo, J. Cui, K. Liang, G. H. Choi, J. P. Yoo, B. G. D. Geest and F. Caruso, ACS Appl. Mater. Interfaces, 2016, 8, 7449-7455.

48 X. Yang, H. Sun, A. Pal, Y. Bai and L. Shao, ACS Appl. Mater. Interfaces, 2018, 10, 29982-29991.

49 H. Sun, X. Yang, Y. Zhang, X. Cheng, Y. Xu, Y. Bai and L. Shao, J. Membr. Sci., 2018, 563, 22-30.

50 J. Zuo, Y. Wang, S. P. Sun and T. S. Chung, J. Membr. Sci., 2012, 405, 123-133.

51 X. Wei, J. Hong, S. Zhu, J. Chen and B. Lv, J. Mater. Sci., 2017, 52, 11701-11714.

52 Z. Thong, Y. Cui, Y. K. Ong and T. S. Chung, ACS Sustainable Chem. Eng., 2016, 4, 5570-5577. 